\title{
Nanocomposite field effect transistors based on zinc oxide/polymer blends
}

\author{
Zong-Xiang Xu and V. A. L. Roy ${ }^{a), b)}$ \\ Department of Chemistry and HKU-CAS Joint Laboratory on New Materials, The University \\ of Hong Kong, Pokfulam Road, Hong Kong Special Administrative Region, Hong Kong \\ Peter Stallinga \\ Universidade do Algarve, 8005-139 Faro, Portugal \\ Michele Muccini and Stefano Toffanin \\ CNR-ISMN, Istituto per lo Studio dei Materiali Nanostrutturati, 40129 Bologna, Italy \\ Hei-Feng Xiang and Chi-Ming Che ${ }^{\mathrm{a}), \mathrm{c})}$ \\ Department of Chemistry and HKU-CAS Joint Laboratory on New Materials, The University \\ of Hong Kong, Pokfulam Road, Hong Kong Special Administrative Region, Hong Kong
}

(Received 15 November 2006; accepted 24 April 2007; published online 1 June 2007)

\begin{abstract}
The authors have examined the field effect behavior of nanocomposite field effect transistors containing $\mathrm{ZnO}$ (zinc oxide) tetrapods or nanocrystals dispersed in a polymer matrix of poly[2-methoxy,5-(2-ethylhexyloxy)-1,4-phenylenevinylene] (MEH-PPV). The electrical characteristics of $\mathrm{ZnO}$ tetrapods/MEH-PPV composite devices exhibit an increase in hole mobility up to three orders of magnitude higher than the polymer MEH-PPV device. (C) 2007 American Institute of Physics. [DOI: 10.1063/1.2740478]
\end{abstract}

Nanocomposite materials are of growing interest particularly for their potential practical applications in various electronic devices, especially light-emitting diodes and photovoltaics. ${ }^{1}$ Despite these advances, using nanocomposite materials for organic field-effect transistor (OFET) applications remain scarce. OFETs have been recently reported in the fabrication of active-matrix displays and integrated circuits for logic and memory chips. ${ }^{2}$ Even though numerous reports exist in this area, OFET devices based on nanocomposite materials fabricated using solution processing are still not well known. In this context, dispersing nanomaterials in a polymer matrix to obtain solution processed devices with a high mobility is of interest for both basic research and application.

In this work, we dispersed $\mathrm{ZnO}$ nanocrystals or tetrapods in the poly[2-methoxy,5-(2-ethylhexyloxy)-1,4-phenylene vinylene] (MEH-PPV) polymer matrix for the construction of inorganic/organic hybrid devices for OFET applications. We chose $\mathrm{ZnO}$ nanomaterials and MEH-PPV polymer because these two materials are widely studied for their intriguing optoelectronic properties. ${ }^{3}$ In literature, there have been reports on inorganic tetrapods mixed with polymers to fabricate hybrid photovoltaic devices. ${ }^{4}$ Herein, the electrical properties of solution processed MEH-PPV $\mathrm{ZnO}$ nanocomposite devices have been found to have enhanced $p$-type mobility up to three orders of magnitude higher than the polymer MEH-PPV device.

The $\mathrm{ZnO}$ nanocrystals were prepared via a modified $\mathrm{Pa}-$ cholski's method. ${ }^{5}$ An ethanol solution of sodium hydroxide $(\mathrm{NaOH})(0.3 \mathrm{M}, 20 \mathrm{ml})$ was slowly added to a solution of zinc (II) nitrate hexahydrate $\mathrm{Zn}\left(\mathrm{NO}_{3}\right)_{2} \cdot 6 \mathrm{H}_{2} \mathrm{O}$ in ethanol $(0.3 \mathrm{M}, 10 \mathrm{ml})$ at $0{ }^{\circ} \mathrm{C}$ which was vigorously stirred for $2 \mathrm{~h}$, and subsequently heated further for $2 \mathrm{~h}$. A precipitate of

\footnotetext{
a) Authors to whom correspondence should be addressed.

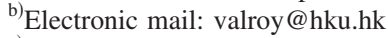

${ }^{c)}$ Electronic mail: cmche@hku.hk
}

nanocrystals was obtained, which was washed with ethanol and toluene.

$\mathrm{ZnO}$ tetrapods were synthesized according to a procedure described in Ref. 6. In a typical synthesis, about $0.5 \mathrm{~g}$ of pure $\mathrm{Zn}(99.99 \%)$ was kept in an alumina boat as a source material. Later the source was transferred into a long quartz tube. A tube furnace with the temperature ramped up to $1000^{\circ} \mathrm{C}$ at a rate of $\sim 50{ }^{\circ} \mathrm{C} / \mathrm{min}$ was used for chemical vapor deposition and the tube furnace was kept at $1000{ }^{\circ} \mathrm{C}$ for more than 20 min under a constant flow of nitrogen and oxygen mixture (1:1). The $\mathrm{ZnO}$ tetrapods were formed by moving the quartz tube inside the tube furnace to place the alumina boat with the source at the heating center $\left(1000{ }^{\circ} \mathrm{C}\right)$ for around $20 \mathrm{~min}$. After the furnace was cooled to room temperature, the $\mathrm{ZnO}$ tetrapods were removed.

A number of different nanocomposites have been made that contained $\mathrm{ZnO}$ nanocrystals or tetrapods dispersed in the polymer matrix, MEH-PPV. In this work, the nanocomposites which contained polymer with nanocrystals or terapods were made in various conditions with the following weight proportions: $10 \mathrm{mg}$ of polymer to $X \mathrm{mg}$ of $\mathrm{ZnO}$ tetrapods or nanocrystals where $X=1,3,5,7,9$, and 10 . Therefore, the weight percentage of $\mathrm{ZnO}$ in MEH-PPV polymer in these devices are $9 \%, 23 \%, 33 \%, 41 \%, 47 \%$, and $50 \%$ respectively. The $\mathrm{ZnO}$ tetrapods or nanocrystals were dispersed in a toluene solution of MEH-PPV (molecular weight of 500000 from H.W. Sands Co.) using an ultrasonic bath.

The transistors were fabricated on bottom-gate transistor structure with a spin coated $\mathrm{ZnO} /$ polymer nanocomposite thin film as active layer. Gate oxide $\mathrm{SiO}_{2}$ layer $(100 \mathrm{~nm}$, relative permittivity $=3.9$ ) was thermally grown on heavily doped $n$-type $\mathrm{Si}$ substrates (the gate electrode). An image reversal photolithography technique was used to form an opening on the photoresist layer for the source and drain patterns on the gate oxide. Source and drain metal layers, consisting of Ti adhesion film (10 nm, lower) and Au conductive film $(50 \mathrm{~nm}$, upper), were deposited by thermal evaporation. After metal film deposition, a standard lift-off 


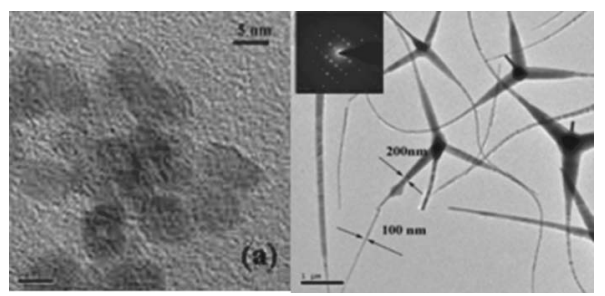

FIG. 1. TEM images of (a) $\mathrm{ZnO}$ nanocrystals and (b) $\mathrm{ZnO}$ tetrapods dispersed in MEH-PPV [the inset picture shows a selected area electron diffraction (SAED) pattern of tetrapods].

process in acetone was used to remove the metal film on top of the photoresist pattern, leaving behind the $\mathrm{Ti} / \mathrm{Au}$ source/ drain contact patterns. The transistor output and transfer characteristics were measured with a probe station under a nitrogen atmosphere using a Keithley K4200 semiconductor parameter analyzer. The transistor channel length and widths were 10 and $600 \mu \mathrm{m}$, respectively.

The fabricated devices that contained a layer of $\mathrm{MEH}-$ PPV only exhibited $p$-channel behavior with a hole mobility up to $10^{-4} \mathrm{~cm}^{2} / \mathrm{V} \mathrm{s}$, similar to those previously reported. ${ }^{3}$ Figures 1(a) and 1(b) show the transmission electron microscope (TEM) images of $\mathrm{ZnO}$ nanocrystals or tetrapods dispersed in MEH-PPV solutions, respectively. The size of the nanocrystals is around $5 \mathrm{~nm}$ [Fig. 1(a)] and the legs of the tetrapods are around $100 \mathrm{~nm}$ in width [Fig. 1(b)]. Figure 2 shows the electrical behavior of the devices fabricated from MEH-PPV and nanocomposite with $\mathrm{ZnO}$ nanocrystals or tetrapods. In Fig. 2, the $I-V$ characteristics and the transfer curves of the devices based on MEH-PPV [Figs. 2(a) and 2(b)] $9 \mathrm{mg}$ of $\mathrm{ZnO}$ nanocrystals in $10 \mathrm{mg}$ of MEH-PPV or $47 \%$ of $\mathrm{ZnO}$ in weight [Figs. 2(c) and 2(d)] and $9 \mathrm{mg}$ of $\mathrm{ZnO}$ tetrapods in $10 \mathrm{mg}$ of $\mathrm{MEH}-\mathrm{PPV}$ or $47 \%$ of $\mathrm{ZnO}$ in weight [Figs. 2(e) and 2(f)], are depicted. A saturation of the hole mobility is observed in the nanocomposite devices when the concentration of $\mathrm{ZnO}$ tetrapods or nanocrystal exceeds $40 \%$ in weight, as shown in Fig. 3. From the $I-V$ characteristics, incorporation of $\mathrm{ZnO}$ nanocrystals or tetrapods in the polymer enhances the drain current and the mobility. The calculated hole mobility was up to $0.08 \mathrm{~cm}^{2} / \mathrm{V} \mathrm{s}$ for the $\mathrm{ZnO}$
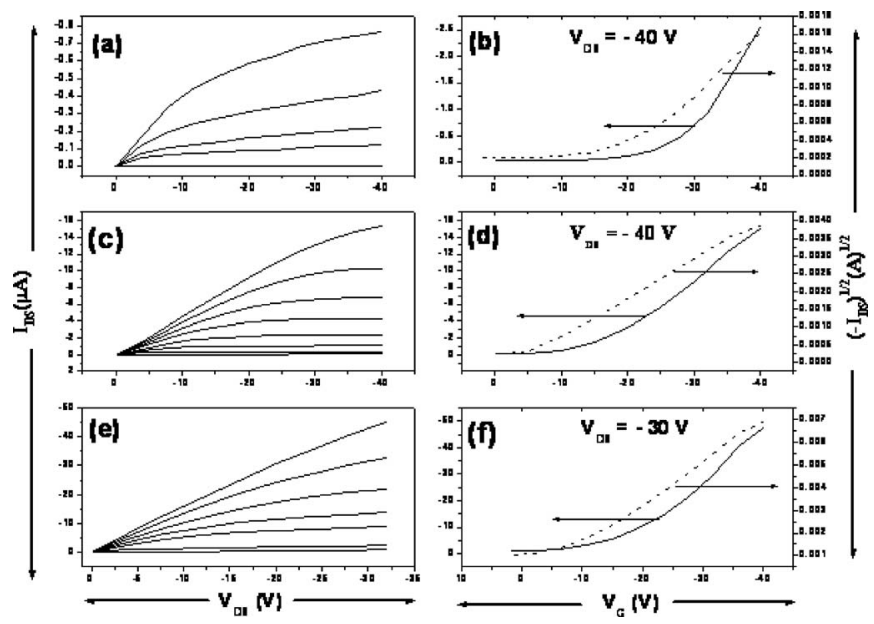

FIG. 2. $I-V$ characteristics and the transfer curves for devices containing MEH-PPV [(a) where $V_{\mathrm{GS}}=0,-25$ to $-40 \mathrm{~V}$ in steps of $5 \mathrm{~V}$ and (b) where $V_{\mathrm{DS}}=-40 \mathrm{~V}$ ], $9 \mathrm{mg}$ of nanocrystals in $10 \mathrm{mg}$ of MEH-PPV [(c) where $V_{\mathrm{GS}}=0$ to $-40 \mathrm{~V}$ in steps of $5 \mathrm{~V}$ and $(\mathrm{d})$ where $\left.V_{\mathrm{DS}}=-40 \mathrm{~V}\right]$, and $9 \mathrm{mg}$ of $\mathrm{ZnO}$ tetrapods in $10 \mathrm{mg}$ of MEH-PPV [(e) where $V_{\mathrm{GS}}=0$ to $-30 \mathrm{~V}$ in steps of $5 \mathrm{~V}$ and (f) where $V_{\mathrm{DS}}=-30 \mathrm{~V}$ ], respectively.

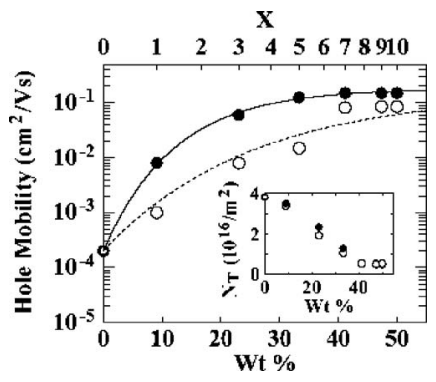

FIG. 3. Correlation between the mobility and the concentration of $\mathrm{ZnO}$ in the form of nanocrystals (solid circles) or tetrapods (open circles) in MEHPPV. The lines are guides to the eye. The inset shows the density of traps as a function of $\mathrm{ZnO}$ concentration, calculated on basis of the found threshold voltage, $N_{T}=-V_{T} C_{\mathrm{ox}} / q$. We propose that the increased mobility is mainly due to the reduction of traps in MEH-PPV.

nanocrystals/MEH-PPV devices and up to $0.15 \mathrm{~cm}^{2} / \mathrm{V}$ s for the $\mathrm{ZnO}$ tetrapods/MEH-PPV devices, at the saturation regime. Whereas in the linear regime, the hole mobility was up to $0.071 \mathrm{~cm}^{2} / \mathrm{V}$ s for the $\mathrm{ZnO}$ nanocrystals/MEH-PPV devices and up to $0.096 \mathrm{~cm}^{2} / \mathrm{V}$ s for the $\mathrm{ZnO}$ tetrapods/MEHPPV devices. A decrease in the threshold voltage up to $-15 \mathrm{~V}$ was found for both nanocomposite devices ( $\mathrm{ZnO}$ nanocrystals or $\mathrm{ZnO}$ tetrapods/MEH-PPV). The subthreshold swing was found to be $2 \mathrm{~V} /$ decade for the $\mathrm{ZnO} / \mathrm{MEH}-\mathrm{PPV}$ nanocomposite devices and up to $10 \mathrm{~V} /$ decade for the $\mathrm{MEH}$ PPV devices. The on/off ratio was calculated as $10^{5}$ for the nanocomposite devices where it was only $10^{3}$ for MEH-PPV devices. Furthermore, a reduction in density of traps, given by $N_{T}=-V_{T} C_{\text {ox }} / q$, has been observed, as shown in the inset of Fig. 3, while the weight percentage of $\mathrm{ZnO}$ increases in the polymer. However, the trap density seems to saturate when the concentration of $\mathrm{ZnO}$ tetrapods or nanocrystal in the polymer exceeds $40 \%$ in weight.

Incorporation of $\mathrm{ZnO}$ nanomaterials (nanocrystals or tetrapods) into the MEH-PPV polymer-a $p$-type semiconductor-did not change the nature of charge transport, as the nanocomposite devices were found to behave as $p$-channel transistors. However, the hole mobility was enhanced in the nanocomposite devices. We also fabricated $\mathrm{ZnO}$ tetrapod devices, containing only $\mathrm{ZnO}$ tetrapods, by drop casting the solution of $\mathrm{ZnO}$ tetrapods dispersed in ethanol on a bottom contact device. The aggregated tetrapods exhibited ambipolar behavior (Fig. 4, available at supplementary information ${ }^{7}$ ) as evidenced from their electrical characteristics in which case the current increased at higher gate voltages in both positive and negative drain-source voltages. Since a clear saturation was not observed in both the positive and negative gate biases, the charge mobility was calculated from the linear regime and it was found to be $10^{-3} \mathrm{~cm}^{2} / \mathrm{V} \mathrm{s}$ for holes. This value is lower than the $\mathrm{ZnO}$ tetrapods/MEH-PPV composite devices. Moreover, no electron current was observed in these composite devices. This indicates that charge transport takes place only in the MEH-PPV polymer. In addition, the energy diagrams of MEH-PPV and $\mathrm{ZnO}$ are well known. The highest occupied molecular orbital $(5.3 \mathrm{eV})$ and lowest unoccupied molecular orbital $(3.0 \mathrm{eV})$ levels of MEH-PPV and the valence $(7.6 \mathrm{eV})$ and conduction $(4.4 \mathrm{eV})$ bands of $\mathrm{ZnO}$ show clearly that a huge energy barrier exists for holes to be transferred from $\mathrm{ZnO}$ to $\mathrm{MEH}-\mathrm{PPV}$ for transport. ${ }^{8}$ Consequently, holes are confined in MEH-PPV and we suggest that the effect of $\mathrm{ZnO}$ is to reduce the density of traps in the 
polymer which probably is a reason for the enhanced mobility and the reduced threshold voltage.

Photoluminescence (PL) measurements were done for $\mathrm{ZnO}$ tetrapods, $\mathrm{MEH}-\mathrm{PPV}$, and $\mathrm{ZnO}$ tetrapods/MEH-PPV composite films (Fig. 5, available at supplementary information $^{7}$ ). The PL measurements explained that the surface state green emission from the $\mathrm{ZnO}$ tetrapods was quenched in the composite film. This suggests that the polymer MEH-PPV covered the surface of $\mathrm{ZnO}$ tetrapods; the latter were distributed randomly in the MEH-PPV polymer matrix. The nonaggregated and nonoriented (random) distributions of $\mathrm{ZnO}$ tetrapods in MEH-PPV matrix have also been observed from the TEM image [Fig. 1(b)]. Hysteresis measurements [Figs. 6(a) and 6(b), available at supplementary information ${ }^{7}$, a close loop measurement by scanning $V_{\mathrm{GS}}$ from 0 to $-40 \mathrm{~V}$ and back to $0 \mathrm{~V}$ with constant drainsource voltage, for both MEH-PPV and $\mathrm{ZnO}$ tetrapods/ MEH-PPV composite devices have been undertaken in this work. Since the backward curve falls below the forward one there is an increase in threshold voltage during operation of the MEH-PPV device. The MEH-PPV device significantly exhibited more hysteresis effect than the $\mathrm{ZnO}$ tetrapods/ MEH-PPV composite devices. In literature, there are several reports revealing that the planar charge transport and charge mobility of OFET devices are affected by the presence of "traps" in the organic semiconductors. ${ }^{9}$ In this work, we did transient measurements where a constant voltage was applied to the gate and drain $(-30 \mathrm{~V})$, while the current was measured as a function of time on the MEH-PPV and $\mathrm{ZnO}$ tetrapods/MEH-PPV devices. The results are depicted in Fig. 7 at the supplementary information ${ }^{7}$. The decrease in the channel current with time is much more dramatic for the MEH-PPV than for the $\mathrm{ZnO}$ tetrapods/MEH-PPV devices. This finding, together with considerably less hystersis effects observed for the composite device depicted in Fig. 6(b), suggests that trapping is reduced in the $\mathrm{ZnO}$ tetrapods/MEHPPV devices. We suggest that a reduction of the density of traps (Fig. 3) is probably the reason for the increased performance of the devices. ${ }^{10}$ The nanocomposite devices with high $\mathrm{ZnO}$ concentration ( $\mathrm{ZnO}$ tetrapod to polymer weight ratio above 5:10) were found to be stable for more than a month.

In summary, we have fabricated $\mathrm{ZnO} / \mathrm{MEH}-\mathrm{PPV}$ based nanocomposite devices with enhanced $p$-channel FET characteristics by a simple solution processing approach. Devices containing various concentrations of $\mathrm{ZnO}$ nanomaterials (tetrapods and nanocrystals) in MEH-PPV were fabricated and analyzed. This revealed that incorporation of $\mathrm{ZnO}$ nanomaterials into the polymer matrix enhances the hole mobility of the devices by up to three orders of magnitude. For the $\mathrm{ZnO}$ nanocrystals/MEH-PPV composite device, the hole mobility is up to $0.08 \mathrm{~cm}^{2} / \mathrm{V} \mathrm{s}$ and for $\mathrm{ZnO}$ tetrapods/MEH-PPV composite device is up to $0.15 \mathrm{~cm}^{2} / \mathrm{V} \mathrm{s}$. We note that current hysteresis was significantly reduced in $\mathrm{ZnO}$ tetrapods/MEHPPV composite devices in contrast to the hysteresis effect observed for the MEH-PPV devices.

This work was supported by the Joint Research Scheme NSFC/RGC (N_HKU 742/04) and University Development Fund (Nanotechnology Research Institute, 00600009) of The University of Hong Kong. Support from Hung Hing Ying funding, HKU [see funding (200511159003)], ITF (GHP/ 062/05), Italian MIUR Project (FIRB-RBNE033KMA), Portuguese POCTI/FAT/47956/2002, and Strategic theme on organic opto-electronics is gratefully acknowledged.

${ }^{1}$ C. Sanchez, B. Julian, P. Belleville, and M. Popall, J. Mater. Chem. 15, 3559 (2005); W. J. E. Beek, M. M. Wienk, and R. A. J. Janssen, Adv. Mater. (Weinheim, Ger.) 16, 1009 (2004); C. Melzer, E. J. Koop, V. D. Mihailetchi, and P. W. M. Blom, Adv. Funct. Mater. 14, 865 (2004).

${ }^{2}$ B. Comiskey, J. D. Albert, H. Yoshizawa, and J. Jacobson, Nature (London) 394, 253 (1998); J. M. L. Chabinyc and A. Salleo, Chem. Mater. 16, 4509 (2004).

${ }^{3}$ R. F. Service, Science 276, 895 (1997); T. Aoki, Y. Hatanaka, and D. C. Look, Appl. Phys. Lett. 76, 3257 (2000); H. Ohta, K. Kawamura, M. Orita, M. Hirano, N. Sarukura, and H. Hosono, ibid. 77, 475 (2000); R. L. Hoffman, B. J. Norris, and J. F. Wager, ibid. 82, 733 (2003); B. J. Norris, J. Anderson, J. F. Wager, and D. A. Keszler, J. Phys. D 36, L105 (2003); E. J. Meijer, D. M. Deleeuw, S. Setayesh, E. Vanveenendaal, B. H. Huisman, P. W. M. Blom, J. C. Hummelen, U. Scherf, and T. M. Klapwijk, Nat. Mater. 2, 678 (2003); L. L. Chua, J. Zaumseil, J. F. Chang, E. C. W. Ou, P. K. H. Ho, H. Sirringhaus, and R. H. Friend, Nature (London) 434, 194 (2005).

${ }^{4}$ B. Sun, E. Marx, and N. C. Greenham, Nano Lett. 3, 961 (2003).

${ }^{5}$ C. Pacholski, A. Kornowski, and H. Weller, Angew. Chem., Int. Ed. 41, 1188 (2002).

${ }^{6}$ V. A. L. Roy, A. B. Djurišić, W. K. Chan, J. Gao, H. F. Lui, and C. Surya, Appl. Phys. Lett. 83, 141 (2003).

${ }^{7}$ See EPAPS Document No. E-APPLAB-90-067720 for the supplementary information. This document can be reached via a direct link in the online article's HTML reference section via the EPAPS homepage (http:// www.aip.org.pubservs.epaps.html).

${ }^{8}$ A. Hagfeldt and M. Gratzel, Chem. Rev. (Washington, D.C.) 95, 49 (1995).

${ }^{9}$ P. Stallinga, H. L. Gomes, F. Biscarini, M. Murgia, and D. M. J. Leeuw, J. Appl. Phys. 96, 5277 (2004); V. Podzorov, E. Menard, A. Borissov, V. Kiryukhin, J. A. Rogers, and M. E. Gershenson, Phys. Rev. Lett. 93, 086602 (2004).

${ }^{10}$ P. Stallinga and H. L. Gomes, Synth. Met. 156, 1305 (2006). 
Applied Physics Letters is copyrighted by the American Institute of Physics (AIP). Redistribution of journal material is subject to the AIP online journal license and/or AIP copyright. For more information, see http://ojps.aip.org/aplo/aplcr.jsp 